\title{
Unialfas inventam um mundo: criações na oficina das séries iniciaís do Colégio de Aplicação da UFRGS
}

Cíntia N unes

A spessoas sem imaginação podem ter tido asmaisimprevistas aventuras, podem ter visitado asterras mais estranhas. $\mathrm{N}$ ada Ihes ficou. $\mathrm{N}$ ada Ihes sobrou. U ma vida não basta ser apenas vivida: também precisa ser sonhada. ${ }^{1}$

R esumo: Este texto trata do relato de uma oficina realizada nas Séries I niciais do Colégio de A plicação da U FR GS. E ssa oficina tem por objetivo desenvolver, através da construção de uma maquete, um espaço de criação em que as invenções dos alunos extrapolem o próprio território da maquete, bem como fomentar um espaço que privilegie o desenvolvimento da criatividade do aluno e o debate entre os diferentes pontos de vista. O s alunos optaram por criar um país, elaborado ao longo de dez encontros. Tal país éum elemento que possibilita a invenção de personagens, reinvenções das construções com sucatas e até mesmo a realização de um teatro. O s resultados obtidos apontam quea oficina possibilita o desenvolvimento da criatividade dos alunos eo trabalho com diferentes conteúdos de forma lúdica.

Palavras-chave: Criatividade, I nvenções, Personagens, Séries iniciais.

* M estranda em Educação (PPGEDU/U FR GS). Professora substituta das Séries I niciais do Colégio de Aplicação da UFRGS. E-mail: cintiamaninha@gmail.com

1 Mário Quintana - texto de abertura do livro: Lili inventa um mundo. 


\begin{abstract}
A bstract: This text is the report of a workshop being held in the first years of the Colégio de A plicação, at the $U$ niversidade Federal do R io G rande do Sul, U FR GS. It aims at developing, through the construction of a model, a space of creation in which students' inventions extrapolate the model's own territory. I t also promotes an environment dedicated to the development of the students' creativity and the debate among different points of view. Students choseto createa country which is being drawn up over ten meetings. This country is theelement which is enabling theinvention of characters, reinventions with scraps of buildings and even a theater is under construction. The results obtained so far indicate that the workshop allows the development of students' creativity along with the work of different contents in a playful way.
\end{abstract}

Keywords: C reativity, Inventions, Characters, First years.

\title{
As oficinas nas Séries Iniciais do CAp/UFRGS
}

0 presente texto tem por objetivo relatar 0 desenvolvimento da oficina: "U nialfas inventam mundo", a qual está vinculada ao Projeto de Extensão Repensando o UNIALFAS: Propos tas A Iternativas para Séries I niciais - 0 que pode ser mais interes sante na escola que a hora do recreio?. Tal projeto foi criado quando os professores constataram que alguns alunos demonstravam muito interesse pelas atividades voltadas para a brincadeira, como o recreio, e um desinteresse para as atividades em sala de aula. A maioria dos alunos não percebia a escola como um lugar em que há a possibilidade de brincar e aprender ao mesmo tempo. A partir dessas observações, procuramos criar um espaço de ludicidade que pudesse ser interessante como a hora do recreio. Com isso, elaboramos a proposta de oficinas, em que cada professor ministra um tema de seu interesse para alunos das diferentes 
turmas das Séries I niciais. Cada oficina é organizada no total de dez encontros, cada um ocorrendo semanalmente, durante dois períodos. Geralmente, há em torno de oito alunos por oficina.

São confeccionados cartazes, para se fazer a propaganda das oficinas oferecidas. $O \mathrm{~s}$ alunos escolhem as de seu maior interesse, preenchendo uma ficha. A través dessas fichas, é feita a seleção dos alunos por diferentes oficinas.

$\mathrm{N}$ a oficina da qual trata este texto, participam oito alunos, sendo, respectivamente: 3 da Alfa II (2a série), 3 da Alfa III (3a série) e 2 alunos da Alfa IV (4a série).

\section{A inspiração da proposta da oficina}

A proposta desta oficina tem como inspiração o Projeto CIVITAS, criado e executado pelo Laboratório de Estudos em L inguagem, Interação e Cognição/U FR GS, sob coordenação da Professora M argarete Axt. Tal projeto é realizado por meio da formação docente em serviço com professores da terceira e quarta série do Ensino Fundamental. A equipe de pesquisadores procura pensar junto com os professores intervenções na sala de aula que possibilitem a invenção/imaginação dos alunos. Os professores geralmente fazem uso de maquetes, compondo cidades imaginárias e interligando as invenções a partir da utilização de tecnologias digitais.

No entanto, a oficina relatada no presente texto não trata de uma execução do projeto, mas sim de uma inspiração, na medida em que procura criar, junto com os alunos, um espaço, no caso, a maquete, que pode engendrar em variadas criações. Seguindo essa ideia, a oficina iniciou por meio de um debate com os alunos em que eles decidiram o que seria criado na mesma. Para isso, levaram em consideração que essa maquete seria algo vivido por eles, ou seja, as criações poderiam extrapolar o espaço da maquete. 


\section{Proposta da oficina: Unialfas inventam um mundo}

A construção de um "mundo imaginário" é feita utilizando sucatas, as quais representam personagens e lugares, bem como demais elementos, a partir do interesse dos alunos. A construção de personagens e lugares é criada de acordo com a imaginação das crianças, possibilitando espaços de invenções, em que, simples caixas de papel se transformam em catapultas, casas e castelos medievais.

A oficina procura possibilitar espaços de criação e diálogo, tendo a seguinte questão investigativa: Q ue elementos dão indícios que os momentos na oficina possibilitam o desenvolvimento da criatividade nos alunos? Além dessa questão, a oficina proporciona um olhar investigativo com relação ao papel dos personagens no mundo imaginário.

O conceito de criatividade é pensado pelo viés da epistemologia genética, sendo J ean Piaget seu autor principal. Conforme essa teoria, a inteligência é uma criação constante, pois a cada conhecimento novo são construídas novas estruturas. É através da coordenação das ações do sujeito sobre os objetos que são realizadas novas construções, o que é externo ao objeto é adicionado às estruturas do conhecimento. Para Piaget, a criação de algo novo está relacionada à abstração reflexiva. Segundo ele, há dois tipos de abstrações: a empírica, em que as informações são retiradas dos objetos ou das ações do sujeito sobre as características físicas desse, e a abstração reflexiva, a qual se abstrai das próprias ações sobre os objetos. Essas abstrações engendram novas estruturas, por ser um reflexo em um plano superior de algo extraído de um patamar inferior.

N esse sentido, pode-se afirmar que a oficina possibilita um espaço para a criação dos alunos, permitindo uma organização das ações sucessivas sobre os objetos.

O texto que segue é dividido em "cenas". Cada cena trata do relato de algumas experiências que foram vividas durante os encontros na oficina. 
A seguir, apresenta-se, com mais detalhes, a explicação do surgimento da maquete. Será que é simplesmente uma maquete?

\section{Muitos nomes, um país: a fundação de Marygrafe de Crinipe}

\section{Cena 1}

A oficina iniciou com uma hora do conto, com o livro 0 planeta Lilás, de Ziraldo. A partir da história, iniciei questionando os alunos sobre a possibilidade de imaginação e da criação de um espaço que poderia ser um planeta, um mundo, um país, uma cidade etc. Eles optaram por criar um país e falaram que o nome poderia ser a letra inicial de cada integrante da oficina. No entanto, percebemos que o nome ficou muito difícil de ler. A pós esta constatação, um aluno sugeriu: Então vamos colocar as primeiras ślabas do nome de cada um. Fizemos, então, algumas tentativas e achamos que a melhor opção seria $\mathrm{M}$ arygrafe de $\mathrm{C}$ rinipe. Fundamos um país com um único nome, o qual contém um pouco de cada um.

Ao serem questionados sobre o que gostariam que existisse no nosso país, os alunos sugeriram:

Q uealgumas pessoas não fossem mal-educadas.

Fazer os sonhos dos outros, pessoas voando, hospitais, carros voadores, famosos.

M ina, castelo, casa de milho e carne, soldados e cavalos, chineses.

Casas, mercados, shoppings, pessoas.

Eu queria que tivesse passaporte para o nosso país, dança comida e outros.

A lgumas das ideias iniciais dos alunos são criadas nos encontros da oficina. No entanto, muitas das sugestões tomaram outros rumos. $\mathrm{M}$ arygrafe de $\mathrm{C}$ rinipe não pôde ter um planejamento estático, as construções e organização da trama vivida 
pelos alunos ganham novos rumos de acordo com o desenrolar dos encontros.

Durante o primeiro encontro, constatei que nem todos os alunos compreendiam a hierarquização da organização dos territórios. Alguns não tinham ainda constituído a hierarquização de que um estado está dentro de um país e esse, por sua vez, dentro de um continente. Essa observação aguçou o planejamento no encontro seguinte.

\section{Onde estamos?}

\section{Cena 2}

No segundo encontro, trabalhamos com a história: O nde estamos?, que apresenta a organização dos territórios partindo da ideia de inclusão hierárquica, com a inclusão dos seguintes elementos: rua, bairro, cidade, estado, país, continente, e por último, universo. D urante a constatação, fui questionando os alunos a respeito do lugar onde estamos.

A seguir o registro do debate realizado:

Professora: Onde nós estamos no globo?

Alunos da Alfa II: Estamos dentro do globo.

Alunos da Alfa III e IV: N ão! Estamos fora!

No decorrer do debate, foi sendo mostrado o mapamúndi e realizados mais questionamentos. Alguns alunos concluíram que:

0 bairro é menor que a cidade.

A cidade é menor que o Estado.

Ao analisar o continente americano no mapa, um aluno diz "Ele é tão pequeno no globo, mas é tão grande, né?".

Os debates acima mostram as ideias entre alunos de diferentes idades. Para os alunos da Alfa II, foi mais difícil a compreensão da inclusão de classes relativas aos lugares. Também, 
foi possível observar a crença de que nós estamos dentro, e não fora, do globo terrestre.

$\mathrm{N}$ esse mesmo encontro, dois alunos decidiram construir um castelo com caixinhas de papel. Em um primeiro momento, começaram fazendo uma cerca com palitinhos de picolé. Q uando questionados sobre o porquê de fazer a cerca antes do castelo, responderam: "Primeiro vamos fazer a cerca para colocar no castelo, se fizermos o castelo antes não vamos saber o tamanho exato da cerca; a cerca tem que ficar mais larga que o castelo."

A contecimentos como esse ocorreram em muitos momentos da oficina, os alunos, ao agirem sobre os materiais de sucata, vão fazendo experimentações, para verificar se há a possibilidade de criarem o que desejam com o material escolhido. Com isso, acabam fazendo relações de altura, largura e proporção com os diversos materiais.

A lém disso, é necessário um diálogo constante, para que as diferentes ideias sejam do acordo de todos, pois é um país sendo inventado a oito mãos.

D ois alunos dizem: $N$ ós vamos fazer um castelo!

Aluno Pe responde: Não dá! A cidade é moderna!

Professora: Então precisamos conversar e decidir o que podemos fazer.

Aluno Pe: A gente pode fazer outra rua, só que essa rua era medieval.

$M$ ais tarde, o mesmo al uno diz: Eu gostaria que trouxessem colherzinhas de plástico para o próximo encontro, eu vou fazer as catapultas.

\section{E se é medieval, a caixa vira catapulta e o palito, flecha do arqueiro...}

\section{Cena 3}

$\mathrm{N}$ o terceiro encontro, $\mathrm{o}$ aluno $\mathrm{Pe}$, que havia dito no encontro anterior que não seria possível criar um castelo, por ser um mundo moderno, e que, ao discutir com os colegas, sugeriu então 
uma rua medieval, iniciou a construção de uma catapulta. Para construí-la, utilizou uma pequena caixa de papel, uma colher de plástico pequena e um atilho com uma bolinha de papel na ponta. Colocou também quatro tampinhas, para representar as rodas. A pós a construção, o aluno andava pela sala, quando, de repente, parou e perguntou:

Pe: Alguém tem um palito de dente?

Professora: Paraquê?

Pe: Para fazer a flecha do arqueiro.

A partir desse encontro, verifiquei que o aluno passou a se interessar por construções referentes à época M edieval, em muitos momentos, optava por criar arqueiros e dragões e continuar a construção da catapulta.

N esse encontro, observei que o debate entre os colegas suscitou um espaço de criação, no qual um aluno utiliza seus conhecimentos sobre um determinado assunto, criando objetos medievais com materiais simples, como caixas e palitos.

\section{"Agora voa!" 0 papel da criatividade nas ações dos alunos sobre os objetos}

\section{Cena 4}

Enquanto realizavam as construções, os alunos comentavam e discutiam sobre como ficaria o país. Q uestionaram-se entre si sobre quem iria morar nas construções criadas. Em seguida, Pe chama os colegas e diz: "Eu fiz uma catapulta sem rodas, olha aqui! Eu tive uma ideia."

O aluno colocou uma tampa na colher e bateu na ponta do cabo, o que fez com que a tampa fosse jogada para cima. Ele percebeu que, da maneira como havia feito a catapulta, a tampa não voava. A partir disso, agindo sobre o objeto, eliminou as rodas e teve uma nova ideia. 
Esse dado nos permite refletir sobre a ação do aluno de construir algo e depois, em um encontro posterior, pensar sobre o que fez e criar algo novo. Ao refletir sobre o que foi criado e agindo sobre o objeto, surgiu uma nova ideia. De acordo com os estudos de J ean Piaget, quando al guém reflete sobre o que fez, a pessoa não está somente refletindo em um nível superior, mas reconstruindo, em um nível superior, o que já existia. Esse tipo de ocorrência pode ser relacionado ao conceito de abstração reflexiva, pois, conforme o mesmo autor,

(...) a abstração lógico-matemática seráchamada, (...) reflexiva porqueprocede a partir das ações e das operações do sujeito. (...) há uma projecção sobre um plano superior daquilo que é extraído do nível inferior, então trata-se de "reflexo"; e o deuma "reflexão" enquanto reorganização sobreo novo plano. (PIAGET, 1987, p. 54).

A criação da primeira catapulta poderia ser classificada como uma ação sobre o objeto permeada por processos de criação e abstração, a segunda ação, em que há uma nova ideia, poderia ser entendida como uma nova reflexão, porém em um plano já superior ao da primeira ação. Verifica-se, assim, o processo de o aluno agir sobre o objeto e enriquecêlo com novas ideias, engendrando novas reflexões e processos criativos.

\section{E se é moderno, o castelo vira museu...}

\section{Cena 5}

É necessário esclarecer que, durante a construção da maquete, alguns alunos criaram carros, apartamentos, supermercados e outros estavam criando castelo, catapultas e arqueiros. A partir dessa observação, iniciei esse encontro com a seguinte questão:

Professora: Esse país existeem que época?

Alunos: M undo deagora, porquejá está tudo arrumado igual essemundo. 
Professora: E o castelo medieval, como será?

Alunos: Vai ser um museu para lembrar o tempo da era medieval. No museu, pode ter pessoas que se vestem como na era medieval, os guardas.

U m aluno diz: Nós temos que escolher o que nós somos.

Verifiquei que, após várias discussões, os alunos decidiram qual a finalidade do castelo. $\mathrm{N}$ a verdade, a cada encontro, as crianças imaginavam o castelo em uma época medieval, mas alguns realizavam construções de elementos da atualidade. Enquanto alguns pensavam em construir um castelo com soldados, outros realizavam construções mais próximas do cotidiano. Então, após montarmos a maquete, debatemos e juntos decidimos uma finalidade mais adequada para o castelo. U m museu da era medieval representaria o interesse dos dois grupos. E, por fim, recebeu 0 nome de $M$ useu $M$ edieval de $M$ arygrafe de $C$ rinipe.

Além do fato de realizarem outras invenções a partir do castelo, também pensaram no papel dos personagens. Para os alunos, no museu, haveria guardas, e pensaram justamente na implicação de cada um na trama da história traçada a cada encontro. Podemos inferir que os alunos vivenciam de fato as construções por eles criadas.

\section{Personagens de um mundo atual - 0 furto no museu}

\section{Cena 6}

I niciamos com a criação dos personagens, pois, em um encontro antes, comentamos que já era necessário escolher "quem nós somos". Então, os alunos foram escolhendo seus personagens e, ao mesmo tempo, elaborando um conflito n-o país, que mais tarde será representado em forma de teatro. Eles decidiram 
que iria ocorrer um roubo no museu. Em seguida, comentamos sobre um fato atual, o furto à Estação Pinacoteca e ao M useu de Arte de São Paulo (M ASP), no dia 12 de junho de 2008, em que três ladrões entraram, sem serem vistos, e retiraram quadros da parede. A partir disso, pensamos em elaborar uma peça de teatro em que ladrões furtassem um quadro do M useu M edieval de $\mathrm{M}$ arygrafe de $\mathrm{C}$ rinipe.

O s personagens criados foram os seguintes: donas do supermercado, gerente do museu, ladrão, detetives, delegado, líder policial. Cada um desenhou o seu personagem e descreveu as respectivas características.

Enquanto escolhiam os personagens, um aluno disse que queria ser o presidente, mas todos os colegas falaram que ele não poderia ser o presidente, por já ser um personagem e porque se assim o fosse, iria "mandar em tudo". Afastei-me dos alunos, para separar um material e, quando retornei, eles disseram que ele seria sim o presidente. Ao serem questionados sobre o porquê da mudança de opinião, produziu-se a fala, a seguir registrada:

Alunos: Todo mundo votou nele.

Professora: Por quê?

Alunos: Eu votei nele porque ele me deixou andar no touro.

Professora: $M$ as que touro?

Alunos: A h professora, o touro, tu não conhece? Ele está na maquete.

Percebi o quanto as crianças estão vivendo esse país imaginário, realizando inclusive negociações para usufruírem de elementos fictícios.

Foi possível observar também que alguns personagens falam um pouco de cada autor, mesmo que de forma implícita. A seguir, algumas falas que demonstram essa constatação:

$\mathrm{Ma:} O \mathrm{O}$ nome vai ser $\mathrm{K}$ aren, é uma prima minha que mora no $\mathrm{R}$ io de Janeiro.

Pe: O objetivo da minha vidaéser presidente, por isso ébom eu começar desde agora. 


\section{Considerações finais}

Este texto procurou relatar uma experiência que privilegia principalmente a criatividade dos alunos no âmbito da escola, de forma que os conteúdos trabalhados não ficassem explícitos e demarcados. D urante o desenvolvimento da construção da maquete, foram sendo elaboradas diferentes atividades, de acordo com a necessidade dos acontecimentos. D essa forma, as construções foram sendo realizadas em um movimento complexo de ideias, possíveis, através das problematizações do grupo de alunos. Sendo assim, não houve um controle sobre as criações dos alunos, abrindo-se espaços para novas criações.

0 isopor tornou-se um espaço de invenções, que perpassam o espaço do concreto, das sucatas, a caixa virou museu e um roubo acontece. Personagens são inventados, soluções são necessárias.

As fendas que se abrem, a partir do espaço de um simples isopor, geraram reinvenções. Viver em $\mathrm{M}$ arygrafe de $\mathrm{C}$ rinipe requer que uma vida não şa simplesmente vivida, mas sim, sonhada.

\section{Referências}

AXT, M argarete. CIVITAS, a cidadeviva: ou de um espaço para o acontecimento-invenção na escola. In: Educação \& realidade. Porto Alegre Vol. 29, n. 2 (jul./dez. 2004), p. 219-235.

BA R BO SA, Ely. Onde estamos? São Paulo: Paulinas, 1994.

PIAGET, Jean. A psicogênese dos conhecimentos e a sua significação epistemológica In: PIATELLIP ALM AR IN , M assimo (org). Teoriasda linguagem teorias da aprendizagem. Lisboa: E dições 70, 1987.

. Criatividade. In: VASCO N CELO, M ário Sérgio (org.) C riatividade: psicologia, educação e conhecimento novo. São Paulo: M oderna, 2001. 
GARCIA, R olando. Criar para compreender: a concepção piagetiana do conhecimento. In: TEBER O SKY, Ana; TOL CH IN SKY, Liliana (orgs.) Substratum: temas fundamentais em psicologia e educação. Porto Alegre: Artes M édicas, 1997.

QU INTAN A. M ario. Lili inventa um mundo. Porto A legre: M ercado A berto, 1983.

U FR GS/CAp. 2004. H istórico do Projeto U nialfas. D isponível em http:// alfas.cap.ufrgs.br/. A cesso em 29 de junho 2008. 